\title{
Chenin blanc Wine Volatiles and the Intensity of a Guava-like Flavour
}

\author{
P. C. van Rooyen*, P. de Wet**, C. J. van Wyk** and A. Tromp.* \\ * Oenological and Viticultural Research Institute, Private Bag X5026, Stellenbosch 7600 \\ ** Department of Oenology, Faculty of Agriculture, University of Stellenbosch
}

\begin{abstract}
A guava-like flavour occurring in some South African Chenin blanc and Colombard dry white wines was investigated. Headspace volatiles of some of these wines, as well as those of fresh guava fruits, were analysed by means of a gas chromatograph equipped with a "sniffer-detector". In contrast to the headspace concentrate of guava fruits, no single fraction with a typical guava flavour was found in the wines analysed.

The pattern recognition system "ARTHUR" was therefore used to investigate relationships between the more important wine volatiles and the intensity of a guava-like flavour of a set of wines originating from the same Chenin blanc must. Sensory scores for this flavour were used in both category and continuous property analysis in each case. Category and correlation to property plots were used to elucidate the results. Several promising variables and ratios between variables were singled out for further investigation, notably ethyl butyrate and the ratios ethyl butyrate/ethyl decanoate and ethyl butyrate/ethyl octanoate.
\end{abstract}

It has been known for many years that South African white table wines produced from Chenin blanc grapes frequently exhibit a fruity flavour reminiscent of fresh guavas. This flavour, which occasionally also develops in wines made from Colombard grapes, is generally regarded as highly desirable in white table wines, since it adds to their complexity. In fact, it is a general phenomenon that wines displaying the guava-like flavour are usually rated higher by sensory panels than wines lacking it. Many wine makers are interested, therefore, to know which factors affect the intensity and occurrence of this flavour, which is believed to originate during fermentation, since it could not be detected in the grape itself. Experiments were begun to identify the main compound(s) responsible for this flavour, as well as the factors responsible for it's rather sporadic occurrence and varying intensity. The first step in this investigation was to identify any commonly occurring compounds typical of guava aroma in the volatile essence of fresh guava fruits, and in wines with intense guava-like flavours. Subsequently, a pattern recognition analysis was applied to a set of data containing the concentration of a series of volatiles, mainly fermentation products, and "guava-intensity" ratings in order to establish hypotheses regarding relationships of the volatiles with the latter.

\section{MATERIALS AND METHODS}

Wine samples: Twenty-eight Chenin blanc and Colombard wines exhibiting variable guava-like flavour intensities were obtained from wineries representative of several wine regions of South Africa. The wines were kept at $0^{\circ} \mathrm{C}$ until used in order to retard changes in their fermentation bouquet. In addition, 128 experimental wines, with varying intensities of the guava-like flavour and produced in a separate investigation, were also used. The latter wines were made by fermenting Chenin blanc must at different levels of amino nitrogen, oxygen, fermentation temperature and grape solids (Tromp, 1980).

Recovery of volatiles from guava fruits and wines: Fresh, intact, mature guavas were harvested, and the headspace volatiles were slowly displaced by means of a stream of nitrogen gas, which was then passed through a short glass column containing conditioned Poropak $\mathrm{Q}$ according to the method used by Ismail, Tucknott \& Williams (1980). Headspace volatiles of the 28 commercial wines with varying intensities of guava flavour were similarly treated.

Gas chromatographic analysis: For the fractionation of volatiles from guavas and wines a Perkin Elmer 990 gas chromatograph, equipped with dual flame ionisation detectors and a single $3 \mathrm{~m} \times 3 \mathrm{~mm}$ (id) glass column, was used. The latter was packed with $5 \%$ Carbowax 4000 monostearate coated onto Chromosorb G HP (80-100 mesh). A stainless steel splitter was attached to the column outlet so that one part of the gas stream containing the fractionated compounds could pass through the detector. The remainder was conducted through a glass capillary to the outside of the gas chromatograph, where it was continually monitored by smelling and describing the odour impressions of each peak. The identity of most of the wine volatiles and the corresponding volatiles of guavas was determined by relative retention times and sniffing. Quantitative analysis of wine flavour compounds was done by the method described by Marais \& Houtman (1979) using a HP 5840 gas chromatograph.

Sensory evaluation of guava flavour intensity: Sensory evaluations were done by a 10-member panel of experienced wine judges familiar with the guava-like flavour. The wines were olfactorily evaluated on an intensity scale ranging from "not detectable", "weak", "moderate", "strong" to "very strong" with regard to the guava-like flavour. Numeric values ranging from 1 to 5 respectively, were allocated to each rating.

Data preparation and pre-processing: The data matrix was analysed using a batch-process version of the pattern recognition system "ARTHUR" (Harper et al., 1977), executed on a UNIVAC 1110 computer at the University of Stellenbosch.

Measurements of wine volatile concentrations were regarded as "features" (Kwan \& Kowalski, 1980), whereas flavour rating, specifically for the guava-like character, was used as a "continuous property" (Harper et al., 1977) for multiple regression and Princi- 
pal Component Analysis (PCA). It was also used as criterion for categorizing the wines for category analysis. In the latter case two categories were defined, namely high intensity (sensory rating above 2 ) or low intensity (rating below 2).

Before being processed by any of the pattern recognition programmes, all data were scaled using the autoscale method, creating new features, all having a mean of 0,0 and a variance of 1,0 . This removes any inadvertent weighting that may occurr due to the difference in magnitude of the features (Harper et al., 1977).

Continuous property analyses: Using actual sensory scores as the continuous property, the programme LEAST was used to fit the analytical data to the flavour rating. Employing a correlation to property weighting method, the programme SELECT, operating on a principal component principle, was used on the 17 scaled features, as well as for a second run on the ratios of the same data. This method selects highly weighted features for plotting against the flavour intensity or other features.

Principal component analyses: For PCA the programmes KAPRIN, KATRIN and VARVAR were used on categorized data. The programme KAVARI applied the Varimax rotation to PCA vectors to elucidate important features (Preston-Whyte, 1974). A similar run was made employing feature ratios generated by the programme TUNE. To reduce the number of features obtained in this way, the programme SELECT was used to select possible features for plotting.

Category analyses: In order to identify features important to the classification of the wines into groups of flavour intensity, the programmes PLANE (hyperplane separation), LESLT (optimization of category pairs), REGRESS (multidimentional multivariate computing a linear discriminant function), KNN (nearest neighbour analysis based on a distance matrix) and SIMCA (statistical isolinear multiple component analysis) were used (Harper et al., 1977). Separate analyses after using the programmes TUNE and SELECT, as described in the previous paragraph, were also executed with the above mentioned methods.

\section{RESULTS AND DISCUSSION}

Fractionation of headspace volatiles: Although the headspace volatiles from commercial wines with and without guava-like flavours demonstrated distinctive and, in many cases recognisable, odours as they emerged from the gas chromatographic column, none of them was found to be reminiscent of the typical guava flavour. On the other hand, one of the fractions from the headspace concentrate of guava fruits had a typical odour of fresh guavas. This fraction was not found to be present in wines displaying a prominent guava-like flavour. Furthermore, guava headspace concentrates contained appreciable quantities of esters akin to those occurring in wines, e.g. ethyl hexanoate, ethyl octanoate and hexyl acetate, which in terms of their relative concentrations and low odour threshold levels should make a substantial contribution to the overall flavour of guavas.
In view of the fact that these fruity esters were the main compounds commonly occurring in the headspace volatiles of guava fruits and wines with guava-like flavours, it was decided to determine their concentrations in wines quantitatively in order to determine possible relationships with the intensity of the typical guava-like flavour of such wines. This resulted in a data matrix consisting of 28 Chenin blanc and Colombard wines of diverse origin, plus the 128 experimental Chenin blanc wines originating from the same must but subjected to different pre-fermentation treatments. The wines were analysed for 17 volatiles (Table 1), and a sensory rating for the intensity of the guava-like character was obtained for each wine. During the process of exploring the data matrix, a number of methods were applied. With each application an attempt was made to identify important components amongst the 17 studied, which distinguish themselves relative to being in either the high or low categories of guava-like flavour intensity, or to be highly weighted in either an equation fitted to the guava-like flavour intensity, or in a PCA vector able to separate the two categories. However, the application of several pattern recognition analyses like PCA, REGRESS and SIMCA, demonstrated no significant relationships when the mixed data set was used.

TABLE 1

Independent variables determined on 128 Chenin blanc wines

\begin{tabular}{clcl}
\hline $\begin{array}{c}\text { Variable } \\
\text { number }\end{array}$ & Component & $\begin{array}{c}\text { Variable } \\
\text { number }\end{array}$ & Component \\
\hline 1 & ethyl acetate & 10 & $\begin{array}{l}\text { ethyl decanoate } \\
\text { di-ethyl succi- } \\
\text { nate }\end{array}$ \\
2 & ethyl butyrate & 11 & $\begin{array}{l}\text { 2-phenyl ethyl } \\
\text { acetate } \\
\text { hexanoic acid }\end{array}$ \\
3 & i-butanol & 12 & $\begin{array}{l}\text { 2-phenyl ethyl } \\
\text { alcohol }\end{array}$ \\
4 & i-amyl acetate & 13 & 14 \\
5 & i-amyl alcohol & 15 & $\begin{array}{l}\text { octanoic acid } \\
\text { total esters } \\
\text { total alcohols }\end{array}$ \\
7 & ethyl hexanoate & 16 & 17 \\
8 & $\begin{array}{l}\text { hexyl acetate } \\
\text { hexanol }\end{array}$ & & \\
\hline
\end{tabular}

In view of this finding it was decided to limit the study to the data matrix of the experimental wines which originated from the one Chenin blanc must only. This matrix consisted of the analytical data of 128 wines, as well as a guava-like intensity rating for flavour similar to the one mentioned above. The reason for this limitation was to reduce factors which could possibly cause interference in the recognition of patterns in the data.

Simple correlation coefficients: Although generally of limited value in interpreting multi-variable problems, the simple correlation coefficients could give indications of future results. Output from the programme CORREL regarding correlations, with probabilities, is listed in Table 2. Several variables have correlation coefficients above 0,5 and could at a later stage emerge as important variables. 
TABLE 2

Correlation of guava flavour intensity with wine volatiles

\begin{tabular}{lrc}
\hline Variable & $\begin{array}{c}\text { Correlation } \\
\text { coefficient }\end{array}$ & Probability* \\
\hline ethyl acetate & 0,56 & 0,000 \\
ethyl butyrate & 0,70 & 0,000 \\
i-butanol & $-0,30$ & 0,001 \\
i-amyl acetate & 0,59 & 0,000 \\
i-amyl alcohol & $-0,40$ & 0,000 \\
ethyl hexanoate & 0,60 & 0,000 \\
hexyl acetate & 0,49 & 0,000 \\
hexanol & $-0,25$ & 0,005 \\
ethyl octanoate & 0,46 & 0,000 \\
ethyl decanoate & $-0,21$ & 0,019 \\
di-ethyl succinate & 0,04 & 0,679 \\
2 phenyl ethyl acetate & $-0,21$ & 0,016 \\
hexanoic acid & 0,62 & 0,000 \\
2 phenyl ethyl alcohol & $-0,54$ & 0,000 \\
octanoic acid & 0,49 & 0,000 \\
total esters & 0,60 & 0,000 \\
total alcohols & $-0,42$ & 0,000 \\
\hline
\end{tabular}

*Probability that the data could come from an uncorrelated paren population.

Principal component analyses: Designating the codes 1 and 2 to samples having low and high flavour intensities, respectively, PCA was followed by a Varimax rotation (programme KAVARI) of the factor loadings in order to clarify the relative importance of the variables. Plots of the first three factors against one another produced a clear separation of the two categories in several cases. A plot of factor 1 against factor 3 is illustrated in Fig. 1. In all cases where good separations were obtained, factor 1 was mainly responsible, as separations were usually not satisfactory on the other axes. Although there are some misclassified wines in this case, the results are sufficient to serve as a guideline for variable selection, especially when the relatively low resolution given by the two categories and the inherent uncertainties of sensory evaluation are taken into account. Factor loadings for the first three components before and after the Varimax rotation are given in Table 3 .
A total of $84,9 \%$ of the variation could be explained by the first three factors, factor 1 contributing $59,4 \%$. The variables ethyl butyrate, ethyl hexanoate, ethyl octanoate and hexanoic and acid are most heavily weighted in this factor, and can provisionally be singled out at this stage.

Applying the above procedure on scaled ratios of the raw data gave inconclusive results. However, plotting variables selected by the programme SELECT, the latter using variance weight as criterion for priority (Harper et al., 1977), gave clear separations in several cases. The best results were obtained where the ratio ethyl butyrate/ethyl decanoate was plotted against ethyl hexanoate/total alcohols (Fig. 2), and with a plot of ethyl butyrate/ethyl decanoate against hexanoic acid/ibutanol (Fig. 3). Good results were mostly due to the separating power of the first variable.

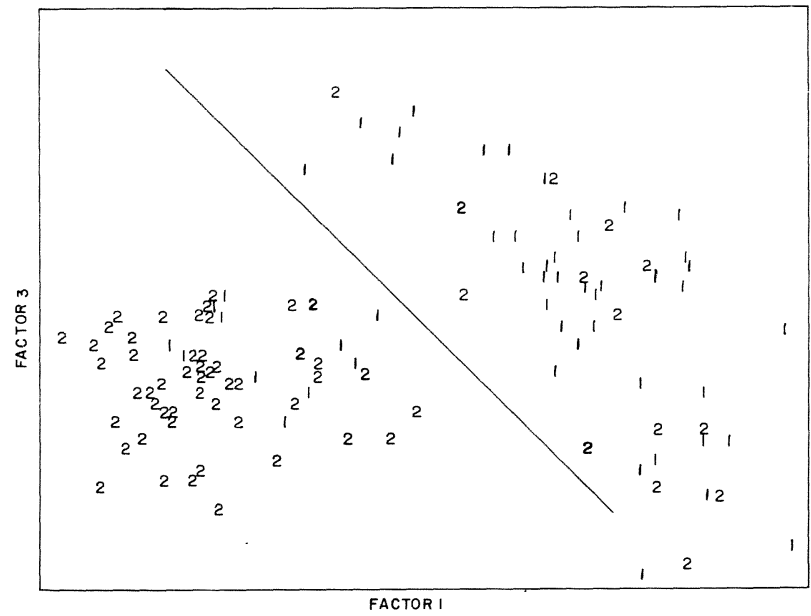

FIG. 1

Plot of factor 1 against factor 3 after PCA on 128 Chenin blanc wines. Code $1=$ low and code $2=$ high "guava" flavour intensity.

TABLE 3

Rotated and unrotated factor loadings after PCA on 17 variables for 128 Chenin blanc wines

\begin{tabular}{|c|c|c|c|c|c|c|}
\hline \multirow{2}{*}{ Variable } & \multicolumn{2}{|c|}{ Factor 1} & \multicolumn{2}{|c|}{ Factor 2} & \multicolumn{2}{|c|}{ Factor 3} \\
\hline & Unrotated & Rotated & Unrotated & Rotated & Unrotated & Rotated \\
\hline ethyl acetate & $-0,28$ & $-0,22$ & $-0,04$ & $-0,26$ & $-0,08$ & $-0,03$ \\
\hline ethyl butyrate & $-0,28$ & $-0,37$ & $-0,11$ & 0,13 & $-0,25$ & 0,11 \\
\hline i-butanol & 0,22 & 0,10 & $-0,31$ & $-0,26$ & $-0,24$ & $-0,56$ \\
\hline i-amyl acetate & $-0,27$ & $-0,32$ & $-0,17$ & 0,10 & $-0,13$ & 0,10 \\
\hline i-amyl alcohol & 0,27 & 0,10 & $-0,24$ & $-0,42$ & $-0,19$ & $-0,19$ \\
\hline ethyl hexanoate & $-0,24$ & $-0,41$ & $-0,28$ & 0,05 & $-0,23$ & 0,00 \\
\hline hexyl acetate & $-0,28$ & $-0,16$ & 0,17 & 0,33 & 0,19 & 0,31 \\
\hline hexanol & 0,15 & 0,09 & 0,21 & $-0,14$ & $-0,41$ & 0,09 \\
\hline ethyl octanoate & $-0,22$ & $-0,37$ & $-0,35$ & 0,11 & 0,01 & $-0,12$ \\
\hline ethyl decanoate & 0,06 & 0,01 & $-0,20$ & $-0,05$ & 0,50 & $-0,01$ \\
\hline di-ethyl succinate & 0,06 & $-0,08$ & $-0,49$ & $-0,12$ & $-0,09$ & $-0,64$ \\
\hline 2 phenyl ethyl acetate & 0,07 & 0,01 & $-0,33$ & $-0,07$ & 0,49 & $-0,11$ \\
\hline hexanoic acid & $-0,30$ & $-0,37$ & $-0,15$ & 0,22 & $-0,08$ & 0,04 \\
\hline 2 phenyl ethyl alcohol & 0,30 & 0,18 & $-0,19$ & $-0,35$ & 0,03 & $-0,17$ \\
\hline octanoic acid & $-0,29$ & $-0,31$ & $-0,12$ & 0,30 & 0,11 & 0,02 \\
\hline total esters & $-0,29$ & $-0,26$ & $-0,07$ & 0,24 & $-0,11$ & $-0,01$ \\
\hline total alcohols & 0,28 & 0,11 & $-0,24$ & $-0,41$ & $-0,18$ & $-0,21$ \\
\hline
\end{tabular}




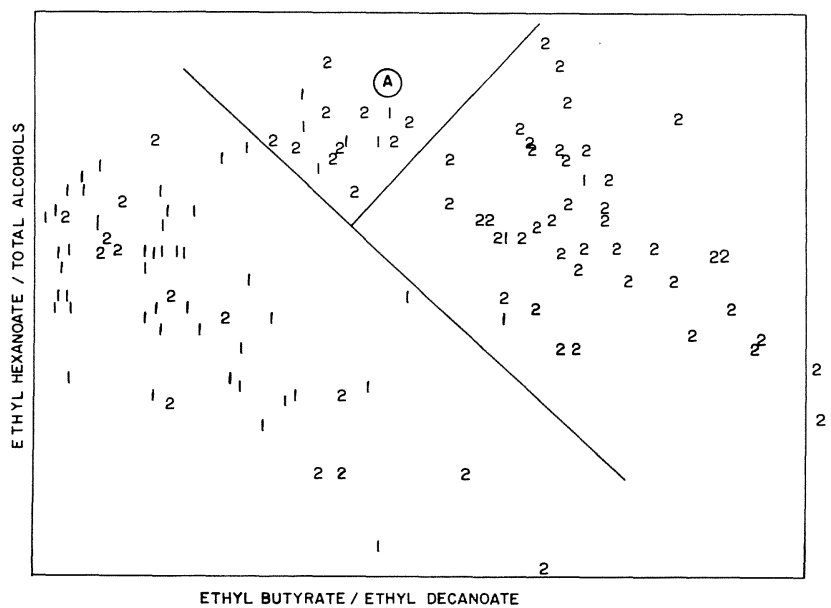

Fig. 2

Plot of two SELECT ratios of scaled, orthonormalized data. Code $1=$ low, and code 2 = high "guava" flavour intensity. Sector "A" constitutes overlapping region.

Continuous property analysis: Summarised results, after fitting a least squares multi-linear regression model to the flavour ratings, and employing the 17 original variables in scaled form, are set out in Table 4 . The fit correlation coefficient was 0,73 . From these results it can be seen that ethyl butyrate, hexyl acetate and total esters had the highest weights in the equation, whereas ethyl butyrate, ethyl hexanoate, hexanoic acid and total esters have high partial correlations with flavour. Ethyl butyrate is undoubtedly much superior in this respect, a result confirmed by analyses reported earlier in this study.

Using the programme SELECT for continuous property analysis, and employing correlation to property weighting for the selection of the 10 best orthonormalised features, ethyl butyrate was again selected as the variable with the greatest weight. A plot of ethyl butyrate as a scaled, orthonormalised feature against guavalike flavour intensity, is given in Fig. 4 and indicates the good relationship between these two variables. Figures

TABLE 4

Standardised weights and partial correlations to flavour for 17 volatiles employing a multilinear regression model

\begin{tabular}{lrr}
\hline Variable & $\begin{array}{c}\text { Weight in } \\
\text { equation }\end{array}$ & $\begin{array}{c}\text { Correlation with } \\
\text { flavour }\end{array}$ \\
\hline ethyl acetate & 1,44 & 0,56 \\
ethyl butyrate & 4,92 & 0,70 \\
i-butanol & 1,04 & $-0,30$ \\
i-amyl acetate & $-0,25$ & 0,59 \\
i-amyl alcohol & 1,69 & $-0,40$ \\
ethyl hexanoate & $-0,11$ & 0,60 \\
hexyl acetate & 2,16 & 0,49 \\
hexanol & $-0,48$ & $-0,25$ \\
ethyl octanoate & 0,29 & 0,46 \\
ethyl decanoate & $-0,46$ & $-0,21$ \\
di-ethyl succinate & 0,39 & 0,04 \\
2-phenyl ethyl acetate & $-0,25$ & $-0,21$ \\
hexanoic acid & 1,70 & 0,62 \\
2-phenyl ethyl alcohol & 0,10 & $-0,54$ \\
octanoic acid & 0,23 & 0,49 \\
total esters & $-2,20$ & 0,60 \\
total alcohols & $-1,14$ & $-0,42$ \\
\hline
\end{tabular}

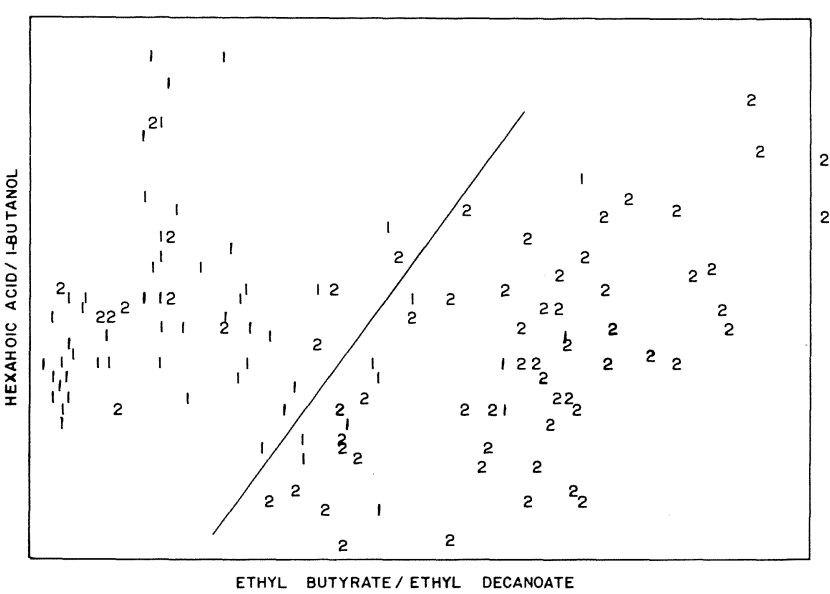

Fig. 3

Plot of two SELECT ratios of scaled orthonormalized data. Codes 1 and 2 for low and high "guava" flavour intensity.

5 and 6, plotting the select features ethyl decanoate and hexanol, respectively, against ethyl butyrate, illustrate a good separation of high and low flavour intensities. The search for meaningful variable ratios using the programmes TUNE, SCALE and SELECT, gave a good relationship between the orthonormalised features ethyl butyrate/ethyl octanoate and the flavour intensity (Figure 7). A relatively good separation between high and low guava-like flavour intensity was obtained by plotting the orthonomalised features ethyl butyrate/ ethyl octanoate against hexanol/i-butanol (Figure 8).

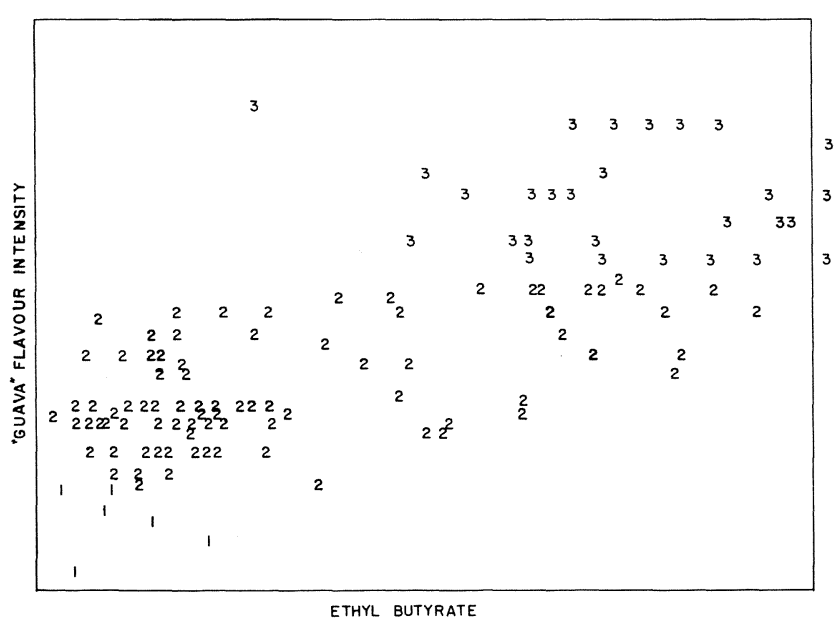

Fig. 4

Plot of autoscaled, orthonormalized SELECT feature ethyl butyrate against "guava" flavour intensity. Codes 1 to 4 represent increasing intensity of "guava" flavour. 


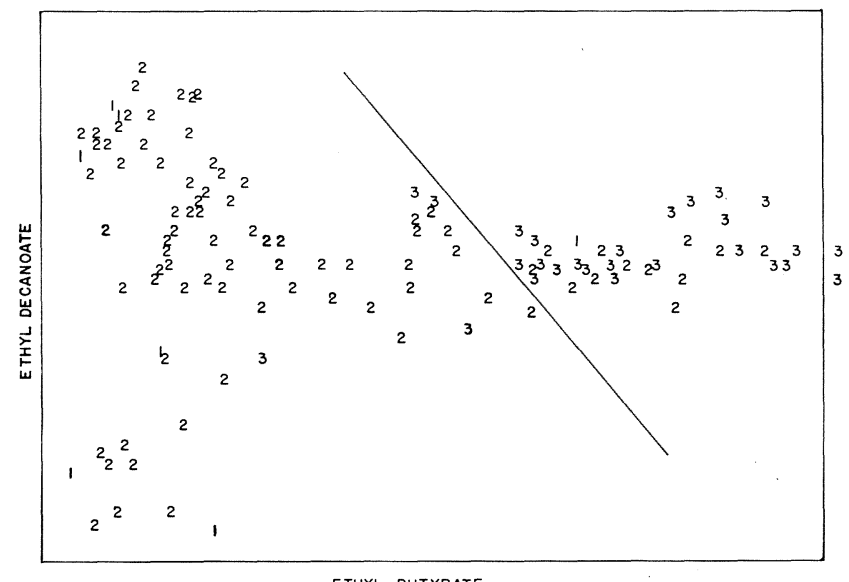

FIg. 5

Plot of SELECT features (autoscaled, orthonormalized) after continuous property analysis employing correlation to property weighting. Codes 1 to 4 represent increasing "guava" flavour intensity.

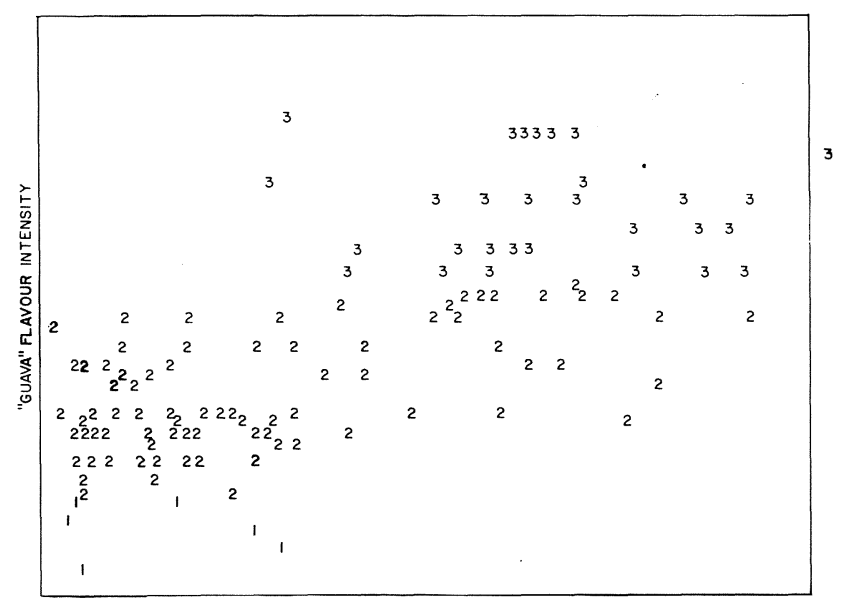

ETHYL BUTYRATE / ETHYL OCTANOATE

\section{FIG. 7}

Plot of an autoscaled orthonormalized SELECT feature ratio after continuous property analysis employing correlation to property weighting. Codes 1 to 4 represent increasing "guava" flavour intensity.

Category classification analyses: A pairwise separation between categories attempted by the programmes PLANE and LESLT, produced a $74,2 \%$ and $84,4 \%$ correct classification, respectively. Relative weights for the 17 standardised original variables are given in Table 5.

In the case of PLANE, the variables ethyl butyrate, hexyl acetate, ethyl octanoate and 2-phenyl ethyl alcohol seem to have the highest discriminatory powers, and in the case of LESLT ethyl butyrate, hexanoic acid and total esters.

Using the programmes REGRESS and SIMCA to calculate discriminant functions for scaled data and employing the two defined categories, $84,4 \%$ and $76,5 \%$ correct classifications were obtained, respectively. The relative weights for the 17 variables are given in Table 6 , establishing once more the relative importance of ethyl butyrate.

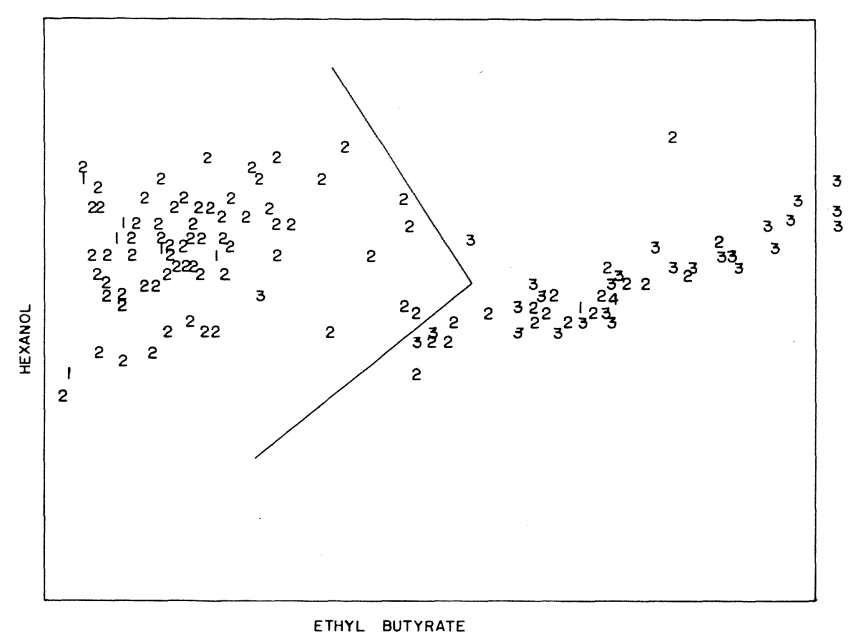

Fig. 6

Plot of SELECT features (autoscaled, orthonormalized) after continuous property analysis employing correlation to property weighting. Codes 1 to 4 represent increasing "guava" flavour intensity.

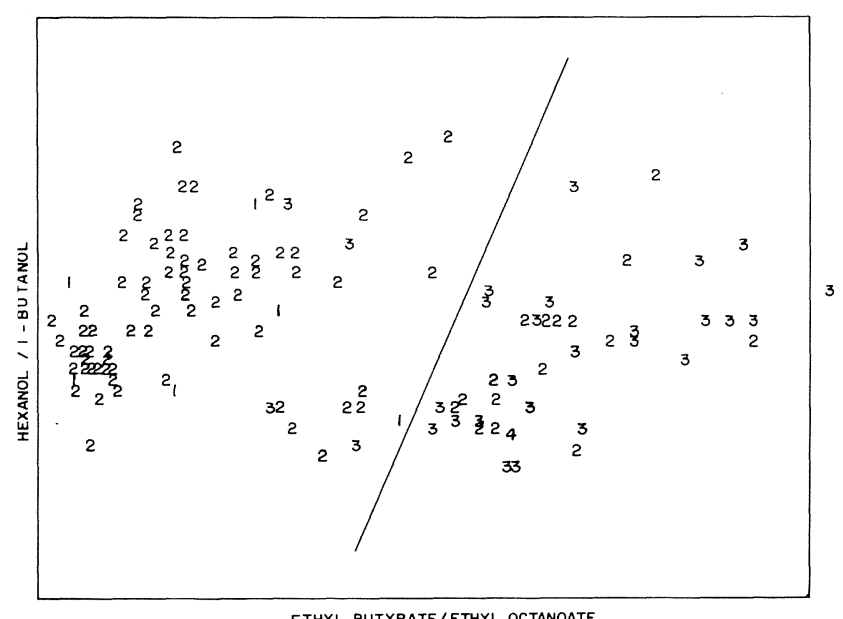

FIG. 8

Plot of two SELECT feature ratios after continuous property analysis employing correlation to property weighting. Codes 1 to 4 represent increasing "guava" flavour intensity.

TABLE 5

Standardised weights for two methods of category classification

\begin{tabular}{lcr}
\hline Variable & $\begin{array}{c}\text { Programme } \\
\text { PLANE }\end{array}$ & $\begin{array}{c}\text { Programme } \\
\text { LESLT }\end{array}$ \\
\hline ethyl acetate & 0,20 & 7,55 \\
ethyl butyrate & 0,32 & 12,80 \\
i-butanol & $-0,19$ & 3,50 \\
i-amyl acetate & 0,05 & 0,06 \\
i-amyl alcohol & $-0,13$ & 7,18 \\
ethyl hexanoate & 0,07 & 2,00 \\
hexyl acetate & $-0,29$ & 4,20 \\
hexanol & 0,01 & 0,25 \\
ethyl octanoate & 0,26 & $-0,22$ \\
ethyl decanoate & $-0,15$ & $-2,13$ \\
di-ethyl succinate & 0,09 & 0,47 \\
2-phenyl ethyl acetate & $-0,19$ & $-1,46$ \\
hexanoic acid & 0,02 & $-12,65$ \\
2-phenyl ethyl alcohol & 0,31 & 3,05 \\
octanoic acid & $-0,19$ & 8,77 \\
total esters & 0,01 & $-10,33$ \\
total alcohol & $-0,11$ & $-8,72$ \\
\hline
\end{tabular}


TABLE 6

Standardised equation weights for discriminant functions

\begin{tabular}{lcc}
\hline Variable & $\begin{array}{c}\text { Programme } \\
\text { Regress }\end{array}$ & $\begin{array}{c}\text { Programme } \\
\text { SIMCA }\end{array}$ \\
\hline ethyl acetate & 3,77 & 1,41 \\
ethyl butyrate & 6,40 & 4,68 \\
i-butanol & 1,75 & 1,46 \\
i-amyl acetate & 0,03 & 1,33 \\
i-amyl alcohol & 3,57 & 1,42 \\
ethyl hexanoate & 0,99 & 1,62 \\
hexyl acetate & 2,10 & 1,07 \\
hexanol & 0,12 & 1,09 \\
ethyl octanoate & $-0,11$ & 1,91 \\
ethyl decanoate & $-1,07$ & 1,75 \\
di-ethyl succinate & 0,24 & 1,03 \\
2-phenyl ethyl acetate & $-0,73$ & 1,11 \\
hexanoic acid & $-6,33$ & 1,66 \\
2-phenyl ethyl alcohol & 1,52 & 1,27 \\
octanoic acid & 4,38 & 1,21 \\
total esters & $-5,17$ & 1,25 \\
total alcohol & $-4,36$ & 1,51 \\
\hline
\end{tabular}

A separate analysis, using the KNN programme on scaled data, also gave satisfactory results. Employing the 5 nearest data vectors as a basis for classification, a correct classification percentage of 76,6 was obtained, proving once more that the data set could be classed into the two categories using the guava-like flavour intensity as norm, and the wine volatiles as variables.

Repeating the category separation analyses, as described above, on feature ratios reduced to ten by the programme SELECT employing variance weighting as criterion of importance as recommended by Harper, et al., (1977), results as set out in Table 7 were obtained.

It is clear from Table 7 that of the 10 ratios selected on a principal component basis by the programme SELECT, only the ethyl butyrate/ethyl decanoate and 2phenyl ethyl alcohol/hexanol ratios show any promise. The importance of the first ratio has already been demonstrated in Figures 2 and 3. Plotting the second select feature did not give conclusive results.

\section{CONCLUSIONS}

Sensory evaluations of individual fractions of headspace extracts, recovered from guava-like flavoured wines, revealed that there existed no analogy between these fractions and the guava-like flavour. However, several of these odorous compounds and their ratios showed a definite relationship with either a classification of guava-like flavour intensity, or on the other hand, correlate significantly with the organoleptic intensity of this flavour. These variables can be listed as follows:
ethyly butyrate
ethyl hexanoate
ethyl octanoate
hexanoic acid
hexyl acetate
2-phenyl ethyl alcohol
total esters
ethyl butyrate/ethyl decanoate
ethyl butyrate/ethyl octanoate

However, throughout the study, the absolute concentration of ethyl butyrate and its concentration relative to that of ethyl decanoate or ethyl octanoate, were by far the outstanding variables to serve as basis for hypotheses in this regard. It must be stressed that this particular flavour could be much more complex, possibly involving other.compounds, and could not conceivably be explained fully by such simple combinations. Du Plessis (1975), for instance, found that absolute concentration increases of ethyl octanoate and ethyl decanoate in existing wines did not influence quality. The important variable in this case could, therefore, be ethyl butyrate, while high levels of the other two esters probably indicate unfavourable conditions for the formation of the guava-like flavour. The usefulness of these results as a base for further study, could be evaluated by observing the effect on the guava-like character in neutral wines by altering their composition in accordance with these results. By changing one or two factors at a time, further evidence could be collected for a better understanding of the phenomenon. External factors, such as the fermentation conditions possibly influencing the production of this particular flavour, should also be investigated.

TABLE 7

Weights of various feature ratios employing four different category classification methods

\begin{tabular}{lrrrr}
\hline \multirow{2}{*}{ Variable } & \multicolumn{3}{c}{ Programme employed } \\
\cline { 2 - 5 } & PLANE & LESLT & REGRESS & SIMCA \\
\hline ethyl butyrate/ethyl decanoate & 0,52 & 7,21 & 3,61 & 6,60 \\
ethyl hexanoate/total alcohols & 0,05 & 1,86 & 0,93 & 1,25 \\
hexanoic acid/i-butanol & $-0,20$ & $-1,77$ & $-0,89$ & 2,34 \\
ethyl decanoate/i-butanol & 0,08 & 1,11 & $-0,56$ & 1,86 \\
octanoic acid/hexanoic acid & $-0,04$ & 1,13 & 0,57 & 1,81 \\
i-butanol/total esters & $-0,04$ & 1,28 & 0,64 & 1,42 \\
ethyl acetate/total esters & 0,10 & 1,08 & 0,54 & 1,53 \\
total esters/ethyl acetate & 0,05 & 1,11 & 0,56 & 2,45 \\
2-phenyl ethyl alcohol/hexanol & $-0,08$ & $-0,86$ & $-0,43$ & 16,51 \\
i-amyl acetate/2-phenyl ethyl alcohol & 0,00 & 0,69 & 0,34 & 2,56 \\
\hline
\end{tabular}




\section{LITERATURE CITED}

DU PLESSIS, C. S., 1977. Fermentation formed components in relation to wine quality. Proc. 4th Int. Symp. Enology, Valencia, Spain, 1975.

HARPER, A. M., DUEWER, D. L., KOWALSKI, B. R. \& FASCHING, J. L., 1977. ARTHUR and experimental data analysis: The heuristic use of a polyalgorithm. "ACS Symposium No. 52". American Chemical Society, Washington DC.

ISMAIL, H. H., TUCKNOTT, O. G. \& WILLIAMS, A. A., 1980 . The collection and concentration of aroma components of soft fruit using Poropak Q. J. Sci. Food Agric. 31, 262-266.

KWAN, W. O. \& KOWALSKI, B. R., 1980. Pattern recognition analysis of gas chromatographic data. Geographic classification of wines of Vitis vinifera $\mathrm{cv}$. Pinot noir from France and the United States. J. Agric. Food Chem. 28, 356-359.

MARAIS, J. \& HOUTMAN, A. C., 1979. Quantitative gas chromatographic determination of specific esters and higher alcohols in wine using freon extraction. Amer. J. Enol. Vitic. 30, 250-252.

PRESTON-WHYTE, R. A., 1974. Climatic classification of South Africa. A multivariate approach. South Afr. Geogr. J. 56, 79-86.

TROMP, A., 1980. Die invloed vań verskillende faktore op gisting en wyngehalte met spesiale verwysing na slepende gisting. Short course in Oenology and cellar planning, 18-20 November 1980, Nietvoorbij. OVRI (internal publication). 